Copyright (C) 2015 by Academic Publishing House Researcher

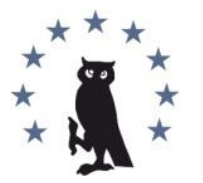

Published in the Russian Federation

European Researcher

Has been issued since 2010.

ISSN 2219-8229

E-ISSN 2224-0136

Vol. 95, Is. 6, pp. 421-428, 2015

DOI: 10.13187/er.2015.95.421

www.erjournal.ru

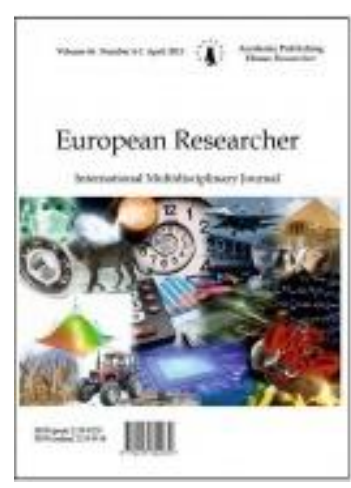

Economic sciences

Экономические науки

UDC 33

\title{
About Some Aspects of Development of the Domestic Market of Services of the Waterway Transport
}

\author{
${ }^{1}$ Marina V. Kogan \\ ${ }^{2}$ Il'ya A. Boytsun
}

\author{
${ }^{1}$ Volga state university of a water transport, Russian Federation \\ $\mathrm{PhD}$ (Economy), associate professor \\ 414000, Astrakhan, Uritsky St., house 17 \\ E-mail: koganpmiop@list.ru \\ ${ }^{2}$ NMSK KAZMORTRANSFLOT LLP, Republic of Kazakhstan \\ $\mathrm{PhD}$ (Technical Sciences), associate professor \\ 30000, Aktau, residential district of the 14th 70 \\ E-mail: I.Boytsun@kmtf.kz
}

\begin{abstract}
One of fundamental factors of development of national economy in modern conditions is a transport complex of the country. The analysis shows, historically raising of many developed countries in many respects was provided with concentration of the state transport policy on optimization of conditions for creation of mass, large-scale transportations that is caused by the acceleration of technical progress involving the growing need of economy for increase in speed of transportations, the tonnage of vehicles, etc.

Territorial reserves of Russia demand harmonious development of all transport complex, including, railway, automobile, air, water.

Shows world experiment, in the countries with such abundance of the rivers, waterways as in Russia one of decisive factors of growth of volumes of transportation of goods and passengers, increase of efficiency of deliveries in scales of all national economy, is the maximum use of a water transport which, other things being equal, manages to the state tens times cheaper than the contents automobile and the railroads.

Currently time for the domestic market of transport services, unlike world, lack of close integration and interrelations in the form of commodity transport complexes with presence of managing directors of the transport centers influencing formation of tariff policy is characteristic.

At the same time the analysis of productivity of a package of measures of tax support of navigation in the Russian Federation, implementation of the FTP "Development of transport system of Russia (2010 - 2020gody)" according to the Concept of long-term social and economic
\end{abstract}


development of the country till 2020 shows their efficiency that is confirmed by positive dynamics of indicators of economic activity of shipping companies, revival of ship-building branch, existence of multiplicative effect due to development of allied industries, revival of business, creation of additional workplaces.

Keywords: Water transport, shipbuilding, market of transport services, internal waterways.

\section{Введение}

Безусловен и очевиден тот факт, что эффективное социально-экономическое развитие каждого государства, нацеленное на выравнивание и поступательное повышение качественного уровня освоения территорий страны, в современных условиях невозможно без параллельного развития как промышленного, так и транспортного комплекса страны.

Надо отметить, что исторически подъем большинства промышленно-развитых стран во многом обеспечивался сосредоточением государственной транспортной политики на оптимизации условий для создания массовых, масштабных перевозок, что обусловлено ускорением технического прогресса, влекущим за собой потребность экономики в увеличении скорости перевозок, тоннажа транспортных средств, их эргономичности [1].

Причем, если в большинстве стран, как и ранее, в Советском Союзе, главной задачей транспортного комплекса является бесперебойное обеспечение потребностей всего народного хозяйства, то в современной России уже сама транспортная отрасль, инвестиции в нее, могли бы повлечь за собой динамичное развитие городов и регионов.

Обусловлено это рядом общеизвестных причин, в числе которых, прежде всего, колоссальные резервы территориального пространства России, что, в свою очередь, требует гармоничного развития всего транспортного комплекса, включая, железнодорожный, автомобильный, воздушный, водный.

Однако изменения структуры экономики страны, произошедшие за последние десятилетия, не могли не отразиться на состоянии отечественной транспортной инфраструктуры и привели к значительному приросту масштабов трубопроводного, автомобильного транспорта на фоне ослабления позиций железнодорожного, воздушного и водного видов транспорта. И если для ряда других стран подобные изменения возможно и являются объективными, необходимыми и своевременными, то для Российской экономики подобный перекос может оказаться губительным, поскольку влечет за собой оживление одних территорий на фоне упадка других в масштабах огромной страны.

Следует отметить, что в Российской Федерации реализуется «Транспортная стратегия России до 2030 года», которая гармонично вписывается в Концепцию долгосрочного социально-экономического развития страны до 2020 года. Основными целями данной стратегии являются не только создание единого транспортного пространства России и обеспечение доступности и качества транспортно-логистических услуг, как в области грузоперевозок, так и в сфере оказания транспортных услуг для населения, но также и повышение безопасности и экологичности всей транспортной системы в целом, а также и «интеграция в мировое транспортное пространство, реализация транзитного потенциала страны» [2].

Рассмотрим основные тенденции развития отечественного рынка транспортных услуг, для чего выделим некоторые характерные особенности современного мирового рынка.

Итак, современный мировой рынок транспортных услуг это усложненная система, в которой все составные части транспортных и логистических процессов интегрированы и взаимосвязаны в виде транспортно-складских и товаро-транспортных комплексов, для которой характерно наличие «управляющих транспортных центров», влияющих на формирование тарифной политики; высокого уровня конкуренции, гарантирующей такой же уровень качества оказываемых транспортных услуг, а также унификация и гармонизация транспортного законодательства [3]. Следует отметить, что вышеперечисленные особенности характерны также и для внутренних рынков транспортных услуг тех стран, где были сформированы и реализуются особые программы развития транспортного комплекса, которым, в свою очередь, со стороны государства уделяется особое внимание и где гармоничное развитие любого вида транспорта зависит от его синхронизации в транспортных узлах. Кроме того, в этих странах, как правило, главной целью стратегий 
развития транспортных компаний является максимальное удовлетворение потребностей клиентов. Иными словами, там, где предприниматели, владельцы транспортных компаний, следуют старой, как история менеджмента, истине «... подлинная цель бизнеса - создавать потребителя» [4], а государство формирует транспортную политику, направленную на эффективное обеспечение всех потребностей народного хозяйства, учитывающую исключение конкуренции между отдельными видами транспорта.

Так, например, во многих странах, на законодательном уровне запрещено дублирование автомобильных, водных, железнодорожных путей, поскольку конкуренция между различными видами транспорта, как уже было отмечено выше, в конечном итоге негативно сказывается на темпах развития всей национальной экономики.

Мировой опыт показывает, в странах с обилием рек одним из решающих факторов роста объемов перевозок грузов и пассажиров, повышения эффективности поставок в масштабах всего народного хозяйства является максимальное задействование речных путей, в том числе и в целях сокращения потребности в текущих расходах на содержание железнодорожных и автомобильных магистралей, поскольку содержание водных путей обходится государству в десятки раз дешевле содержания автомобильных и железных дорог.

Но в России, где, в отличие от европейских и азиатских стран, реки зимой замерзают, и, в том числе, и поэтому, на фоне колоссальных резервов пропускной способности водных путей, присутствует перегрузка автомобильных и железных дорог и принимаются решения о строительстве новых, причем часто параллельно водным путям.

При этом, следует отметить, что в Российской Федерации в последние годы «из-за недофинансирования протяженность внутренних водных путей с гарантированными габаритами судовых ходов сократилась почти на 30 \%» [5], а эксплуатация их отдельных участков стала возможна лишь в светлое время суток.

Государством был предпринят ряд шагов, направленных на исправление сложившейся ситуации, в числе которых подписание в декабре 2014 г. постановления об утверждении новых нормативов на содержание внутренних водных путей и судоходных гидротехнических сооружений, которое открывает все возможности для радикального исправления и улучшения сложившейся ситуации.

Принятие данного документа, а также реализация ФЦП «Развитие транспортной системы России (2010-2020 годы)», Транспортной стратегии Российской Федерации до 2030 года позволяют решить одну из важнейших задач современного периода развития отрасли - устранение лимитирующих участков. По предварительным оценкам, прогнозируемый удельный мультипликативный эффект при этом составит 2,46 руб. на 1 руб. вложений, увеличение протяженности внутренних водных путей с круглосуточным движением с гарантированными габаритами составит 17,9 тыс. км, улучшение габаритов судовых ходов - на 26,4 тыс.км. [8]

При этом величина интегрального мультипликативного эффекта предполагается в объеме 1295 млрд. руб., из которых отраслевой - 116 млрд. руб., в смежных областях 1179 млрд. руб., т.е. не только в создании новых транспортных средств, но и в сопутствующих отраслях: металлургии, обрабатывающих и добывающих производствах, энергетике и пр. [6]

Безусловно, это колоссальный шаг не только в развитии отрасли, но и в развитии экономики страны.

Однако современные процессы индивидуализации потребительского спроса диктуют участникам рынка необходимость регулярных, и бесперебойных поставок товаров (часто малыми партиями) от продавцов (производителей) к покупателям, что весьма сложно обеспечить в России в силу уже описанных нами выше причин (колоссальная протяженность маршрутов, замерзание рек зимой и пр.).

Возможно, выход можно найти в проектировании, строительстве, применении других типов судов. Например, так называемые, автомобилевозы (суда, или баржи), которые, в весенне-летний период, перевозят автотранспортные средства географически максимально ближе к пунктам назначения, а далее уже эти самые автотранспортные средства доставляют товар непосредственно потребителям (розничная торговля, индивидуальные покупатели и пр.). При таком способе организации поставок физический износ автотранспортного средства значительно сокращается, достигается экономия топлива, ГСМ. Также следует 
обратить внимание на опыт применения современных судов на воздушной подушке, которые в зимний период могут передвигаться по льду и пока, в основном, используются в туризме, но уже подтверждают эффективность их применения.

Но здесь нам хотелось бы обратить внимание на такие ключевые, на наш взгляд, словосочетания, как «транспортная компания», «транспортно-складские», «товаротранспортные комплексы», а также «управляющие транспортные центры». Именно транспортная компания, а не судоходная, автомобильная и т.д., имея на балансе различные виды транспорта, сможет обеспечить подобный способ организации поставок товаров потребителям, а управляющие центры в товаро-транспортных комплексах смогут обеспечить как бесперебойность, так и качество поставок уже за счет того, что не судоходные компании будут конкурировать с автомобильными, либо железнодорожными и пр., а транспортные организации друг с другом, что, в конечном итоге, как показывает мировой опыт, ведет и к повышению качества обслуживания, и к снижению издержек.

В любом случае, очевидно, что развитие транспортной системы, водной отрасли в том числе, невозможно без параллельного развития судостроения.

Следует отметить, что за последние годы в России наблюдается оживление отрасли. Так, например, за период с 2004 г. по 2010 г. Онежским судостроительным заводом было построено 12 многоцелевых сухогрузных теплоходов смешанного «река-море» плавания, которые особо востребованы и отечественными современными судоходными компаниями, ориентированными на Российские порты, и компаниями государств Прикаспийского макрорегиона, в силу транзитного положения Каспийского моря, а также потребностей стран Прикаспия (Россия, Азербайджан, Казахстан, Туркменистан, Иран) и других близрасположенных государств (Армения, Турция, Грузия, Узбекистан, Оман, Индия, Афганистан, Пакистан).

В 2014г. крупнейшая судостроительная компания России ОАО «Объединенная судостроительная корпорация» (ОАО «ОСК»), созданная в 2007г., в соответствии с указом Президента России, в которой 100 \% акций находятся в федеральной собственности (около 60 предприятий: основные судостроительные и судоремонтные верфи, ведущие ПКБ) дополнительно приобрела 50 \% акций финской судостроительной компании Arctech Helsinki Shipyard Inc и теперь верфь Arctech Helsinki Shipyard, имеющая богатейший опыт строительства судов ледового класса на 100\% принадлежит ОАО «ОСК». В числе заказов предприятия 6 судов ледового класса, первый из которых, ледокол для Балтийского моря, должен быть передан Министерству транспорта России осенью 2015 г.

При этом для ОАО «ОСК», экспортирующей свою продукцию в 20 стран мира, основным является отечественный рынок.

В 2014 г. в состав России влились два новых субъекта: Республика Крым и город федерального значения Севастополь, для которых, после присоединения, основным рынком сбыта продукции судостроительных и судоремонтных предприятия также стал российский рынок.

Введение США и европейскими странами прямых санкций против Крыма и Севастополя, непризнание международной общественностью Крыма и Севастополя в составе Российской Федерации, почти 90-\% износ основных производственных фондов предприятий судостроительной отрасли полуострова, являются основными факторами риска для развития там коммерческого судостроения. Между тем налоговые льготы, о которых мы расскажем ниже (для российских судовладельцев, купивших новых суда, построенные в Российской Федерации после 1 января 2010г. и зарегистрировавших их в Российском международном реестре судов) могут оказать свое положительное влияние на международном уровне для Крыма и Севастополя. Но все же, на настоящий момент времени, развитие коммерческого судоремонта и судостроения на полуострове затруднено и, в основном, ориентировано на обслуживание российских каботажных компаний, которые не осуществляют международные рейсы и не имеют активов на Западе [7].

Тем не менее в 2014г. на заводе «Залив» (г.Керчь) были заложены два пассажирских судна и два универсальных танкера, предназначенных для перевозки дизельного топлива, мазута, авиационного керосина и т.д. и которые также могут быть задействованы для доставки сухих грузов на надводные корабли, суда и подводные лодки. 1 января 2015 года в 
силу вступил федеральный закон РФ от 29 ноября 2014 г. №377-Ф3 «О развитии Крымского федерального округа и особой экономической зоне на территориях Республики Крым и города федерального значения Севастополя», где установлен особый правовой режим «...в целях обеспечения устойчивого социально-экономического развития, привлечения инвестиций в развитие действующих и создание новых производств, развития транспортной и иных инфраструктура также повышения уровня и качества жизни граждан. [4]

Очевидно, что в сложившихся условиях лишь бюджетное финансирование будет являться основой реализации большинства проектов судостроительных предприятий полуострова: восстановление функционирования крупных предприятий с государственным участием (завод «Море» в г. Феодосия, завод «Залив» в г. Керчь), развитие СРЗ 13 МО РФ в Севастополе; обеспечение заказами отраслевых центрально-конструкторских бюро.

Как уже было отмечено выше «Транспортная стратегия России до 2030 года» предусматривает интеграцию России «в мировое транспортное пространство», а также реализацию ее транзитного потенциала, что, по понятным причинам (Россия имеет выходы к 13 морям, 3 океанам) невозможно осуществить без поддержки развития отечественного морского транспорта.

В этой связи хотелось бы отметить, что в России за последний период также большое внимание уделяется совершенствованию правил Российского Речного Регистра и изучению эффективности функционирования современных организаций водной отрасли. Так, например, в 2014 г. учеными Волжского государственного университета водного транспорта была проведена научно-исследовательская работа по оценке достаточности мер поддержки отечественного судостроения и судоходства, выполненной по заказу Министерства транспорта России, результатом которой явилось обоснование необходимости оказания дополнительной помощи отраслевым предприятиям [8].

Следует отметить, что в Российской Федерации, в целях оживления воспроизводства основных фондов судоходных компаний уже предприняты серьезные шаги, в числе которых меры по созданию специальных международных реестров (РосМРС) для снижения налоговой нагрузки на отечественные специализированные организации. Это, прежде всего, федеральные законы: № 168-Ф3 от 20.12.2005 г. «О внесении изменений в отдельные законодательные акты РФ в связи с созданием РосМРС»; № 305 - ФЗ от 07.11.2011 г. «О внесении изменений в отдельные законодательные акты РФ в связи с реализацией мер государственной поддержки судостроения и судоходства».

Исполнение положений Закона № 168-ФЗ заложило основание для формирования особых, благоприятных условий для отечественных судовладельцев, прежде всего, за счет облегчения налоговой нагрузки. Так, при реализации международных морских поставок собственники могут быть освобождены от уплаты налога на прибыль, транспортного налога, налога на имущество, НДС с импортируемых судов и уплаты на них ввозной таможенной пошлины при условии уплаты госпошлины за регистрацию судна в реестре и ее ежегодного продления [9]. Также, при реализации морских судов, построенных на отечественных верфях, предполагается освобождение от НДС, от уплаты таможенных пошлин при ввозе иностранного оборудования. Но, в то же время, владельцу, снимающему с регистрации судно ранее 10 лет с момента постановки на учет и построенного на отечественной верфи, необходимо уплатить налог на добавленную стоимость, который при покупке судна не взимался.

Тем не менее на начальном этапе в созданном РосМРС было зарегистрировано гораздо менее судов, чем ожидалось и в результате, в 2011 г., в федеральном законе № 305-Ф3 количество преимуществ и льгот собственникам судов уже было значительно увеличено, вплоть до получения льгот судами, сдаваемыми в аренду под перевозку грузов и пассажиров на международных линиях, задействованными и арендуемыми в перевозках и буксировках в каботаже, используемыми для разведки и разработки минеральных и других ресурсов морского дна и его недр, гидротехнических и подводно-технических работ, а также самоходных с главными двигателями мощностью не менее 55 кВт, несамоходных вместимостью не менее 80 единиц, построенных на российских верфях после 1 января 2010 года, в том числе для осуществления торгового мореплавания. Исключение составили 
суда, уже состоящие в иностранных реестрах, а также суда старше пятнадцати лет на момент подачи заявления, а не десяти, как было до принятия закона.

Также очень важным элементом нововведений явилась возможность исключения из фонда амортизируемого имущества при расчете налога на прибыль для судов, зарегистрированных в РосМРС на время нахождения их в реестре, которая позволяет существенно сократить расходную часть (на величину начисленной амортизации) и, следовательно, способствует получению положительных результатов финансовохозяйственной деятельности судоходных компаний.

Надо отметить, что подобный опыт предоставления налоговых льгот судоходным организациям успешно применяется в разных странах, число которых ежегодно пополняется. Так, Казахстан планирует внести изменения в законодательство о водном транспорте страны. Предполагается, что в законе Республики Казахстан «О торговом мореплавании» появятся поправки о создании единого судоходного реестра страны, с применением налоговых и таможенных льгот (освобождение от уплаты налогов тех судоходных компаний, суда которых будут зарегистрированы в данном реестре) [10].

Таким образом, принятие вышеперечисленных нормативных документов позволяет существенно расширить перечень льгот для судоходных компаний, что формирует предпосылки для развития организаций водного транспорта и судостроительных в том числе.

Таким образом, для отечественного рынка транспортных услуг, в отличие от мирового, характерно отсутствие тесной интеграции и взаимосвязей в виде товаро-транспортных комплексов с наличием управляющих транспортных центров, влияющих на формирование тарифной политики.

Как уже было отмечено выше, сложившаяся ситуация во многом объясняется ослаблением позиций железнодорожного и водного транспорта на фоне усилений трубопроводного и автомобильного, присутствием конкуренции между разными видами транспорта, что, в свою очередь, негативно влияет как на формирование тарифной политики, так и на результативность поставок товаров, обеспечение пассажирских перевозок.

Мировой опыт показывает, качество доставки товаров и перевозки пассажиров в современных условиях обеспечивается транспортными компаниями, которые, имея на балансе транспортные средства разных видов (морские, речные суда, грузовые и легковые автомобили и пр.) могут гарантировать скорость, сохранность, надежность и качество грузоперевозок, поставок «под ключ», сэкономив при этом на издержках, в том числе и за счет более низкой себестоимости перевозок речными судами. В свою очередь активное развитие транспортных компаний влечет за собой ускоренное формирование транспортноскладских и товаро-транспортных комплексов с управляющими транспортными центрами в своем составе.

В то же время анализ результативности комплекса мер налоговой поддержки судоходства в Российской Федерации, реализации ФЦП «Развитие транспортной системы России (2010-2020 годы)» в соответствии с Концепцией долгосрочного социальноэкономического развития страны до 2020 года показывает их эффективность, что подтверждается положительной динамикой показателей хозяйственной деятельности судоходных компаний, оживлением судостроительной отрасли.

\section{Примечания:}

1. Федеральный конституционный закон Российской Федерации от 21 марта 2014 г. № 6-ФКЗ «О принятии в Российскую Федерацию Республики Крым и образовании в составе Российской Федерации новых субъектов Республики Крым и города федерального значения Севастополя».

2. Закон от 20.12.2005 г. № 168-ФЗ «О внесении изменений в отдельные законодательные акты РФ в связи с созданием РосМРС» (с дополнениями).

3. Закон от 07.11.2011 г. № 305-Ф3 «О внесении изменений в отдельные законодательные акты РФ в связи с реализацией мер государственной поддержки судостроения и судоходства». 
4. Закон от 29.11.2014 г. № 377-ФЗ «О развитии Крымского федерального округа и особой экономической зоне на территориях Республики Крым и города федерального значения Севастополя.

5. Гусев E.A. Транспортный барьер на пути модернизации страны//Вестник Волжской государственной академии водного транспорта, материалы 3-й МНПК, посвященной 100-летию Пермского речного училища и 50-летию Пермского филиала ФБОУ ВПО «ВГАВТ». 2013.

6. Кобранов С. Новый статус - повышенная ответственность // Речной транспорт (XXI век). 2015. №1.

7. Корень Ю.И. Сущность, принципы и задачи управления развитием водного транспорта с учетом зарубежного опыта // Вестник Волжской государственной академии водного транспорта, материалы 3-й МНПК, посвященной 100-летию Пермского речного училища и 50-летию Пермского филиала ФБОУ ВПО «ВГАВТ». 2013.

8. Крайне необходимый и всесторонне выгодный проект. По материалам прессслужбы Минтранса России, Росморречфлота, ГУМРФ им. адм. С.О. Макарова // Речной транспорт (XXI век). 2015. №1 (72).

9. Мескон М.Х., Альберт М., Хедоури Ф. Основы менеджмента: пер. с англ. М.: Дело, 1992. $702 \mathrm{c}$.

10. Seafarersjornal.com.

\section{References:}

1. Federal'nyi konstitutsionnyi zakon Rossiiskoi Federatsii ot 21 marta 2014 g. № 6-FKZ «O prinyatii v Rossiiskuyu Federatsiyu Respubliki Krym i obrazovanii v sostave Rossiiskoi Federatsii novykh sub"ektov Respubliki Krym i goroda federal'nogo znacheniya Sevastopolya».

2. Zakon ot 20.12.2005g. № 168-FZ «O vnesenii izmenenii v otdel'nye zakonodatel'nye akty RF v svyazi s sozdaniem RosMRS» (s dopolneniyami).

3. Zakon ot 07.11.2011 g. № 305-FZ «O vnesenii izmenenii v otdel'nye zakonodatel'nye akty RF v svyazi s realizatsiei mer gosudarstvennoi podderzhki sudostroeniya i sudokhodstva».

4. Zakon ot 29.11.2014 g. № 377-FZ «O razvitii Krymskogo federal'nogo okruga i osoboi ekonomicheskoi zone na territoriyakh Respubliki Krym i goroda federal'nogo znacheniya Sevastopolya.

5. Gusev E.A. Transportnyi bar'er na puti modernizatsii strany//Vestnik Volzhskoi gosudarstvennoi akademii vodnogo transporta, materialy 3-i MNPK, posvyashchennoi 100-letiyu Permskogo rechnogo uchilishcha i 50-letiyu Permskogo filiala FBOU VPO «VGAVT». 2013

6. Kobranov S. Novyi status - povyshennaya otvetstvennost' // Rechnoi transport (XXI vek). 2015. №1.

7. Koren' Yu.I. Sushchnost', printsipy i zadachi upravleniya razvitiem vodnogo transporta s uchetom zarubezhnogo opyta // Vestnik Volzhskoi gosudarstvennoi akademii vodnogo transporta, materialy 3-i MNPK, posvyashchennoi 100-letiyu Permskogo rechnogo uchilishcha i 50-letiyu Permskogo filiala FBOU VPO «VGAVT». 2013.

8. Kraine neobkhodimyi i vsestoronne vygodnyi proekt. Po materialam press-sluzhby Mintransa Rossii, Rosmorrechflota, GUMRF im. adm. S.O. Makarova // Rechnoi transport (XXI vek). 2015. №1 (72).

9. Meskon M.Kh., Al'bert M., Khedouri F. Osnovy menedzhmenta: per. s angl. M.: Delo, 1992. $702 \mathrm{~s}$.

10. Seafarersjornal.com. 
УДК 33

\title{
О некоторых аспектах развития отечественного рынка услуг водного транспорта
}

\author{
${ }^{1}$ Марина Владимировна Коган \\ ${ }^{2}$ Илья Александрович Бойцун
}

${ }^{1}$ Каспийский институт морского и речного транспорта филиал ФГБОУ ВО «Волжский государственный университет водного транспорта», Российская Федерация

41400о, г. Астрахань, ул. Урицкого, 17

кандидат экономических наук, доцент

E-mail: koganpmiop@list.ru

${ }^{2}$ ТОО «НМСК «КАЗМОРТРАНСФЛОТ»», Республика Казахстан

кандидат технических наук, доцент, начальник службы судостроения

13000о, г. Актау, микрорайон 14, 70

E-mail: I.Boytsun@kmtf.kz

Аннотация. Одним из основополагающих факторов развития национальной экономики в современных условиях является развитие транспортного комплекса страны. Анализ показывает, исторически подъем многих развитых стран во многом обеспечивался сосредоточением государственной транспортной политики на оптимизации условий для создания массовых, масштабных перевозок, что обусловлено ускорением технического прогресса, влекущим за собой растущую потребность экономики в увеличении скорости перевозок, тоннажа транспортных средств и т.д.

Территориальные резервы России требуют гармоничного развития всего транспортного комплекса, включая, железнодорожный, автомобильный, воздушный, водный.

Мировой опыт показывает, в странах с таким обилием рек, водных путей, как в России одним из решающих факторов роста объемов перевозок грузов и пассажиров, повышения эффективности поставок в масштабах всего народного хозяйства, является максимальное использование водного транспорта, который, при прочих равных, обходится в десятки раз дешевле содержания автомобильных и железных дорог.

На настоящий момент времени для отечественного рынка транспортных услуг, в отличие от мирового, характерно отсутствие тесной интеграции и взаимосвязей в виде товаро-транспортных комплексов с наличием управляющих транспортных центров, влияющих на формирование тарифной политики.

В то же время анализ результативности комплекса мер налоговой поддержки судоходства в Российской Федерации, реализации ФЦП «Развитие транспортной системы России (2010 - 2020годы)» в соответствии с Концепцией долгосрочного социальноэкономического развития страны до 2020 года показывает их эффективность, что подтверждается положительной динамикой показателей хозяйственной деятельности судоходных компаний, оживлением судостроительной отрасли, наличием мультипликативного эффекта за счет развития смежных отраслей, оживления бизнеса, создания дополнительных рабочих мест.

Ключевые слова: Водный транспорт; судостроение; рынок транспортных услуг; внутренние водные пути. 